\title{
Bosellia serrata-induced apoptosis is related with ER stress and calcium release
}

\author{
Hyung-Ryong Kim • Myung-Sunny Kim • \\ Dae-Young Kwon $\cdot$ Soo-Wan Chae $\cdot$ Han-Jung Chae
}

Published online: 17 November 2007

(C) Springer-Verlag 2007

\begin{abstract}
It has been reported that the gum resin of Boswellia serrata (BS), which has been shown to have antiinflammatory properties, might also have anticancer effects. This study examined the potential of BS as an anticancer agent. The BS extract induces apoptosis in HeLa human cervical carcinoma cells, as confirmed by two apoptosis analyses, Hoechst staining and Annexin V/PI assay. Among the apoptosis pathways, the ER stressassociated mechanism was examined to determine its role in BS-induced apoptosis. The expression of GRP78 and CHOP, which are representatives of the ER stress proteins, and the calcium-binding protein-calpain were determined. The results showed significantly higher levels of both GRP78 and CHOP, and stronger calpain activity in the BStreated cells than in the control cells. This shows that there is a correlation between ER stress signaling and apoptosis, which suggests the possibility of the BS-ER stress initiator as an anticancer therapeutic agent in human cervical carcinoma.
\end{abstract}

\section{H.-R. Kim}

Department of Dental Pharmacology, School of Dentistry,

Wonkwang University, Iksan, Chonbuk, Republic of Korea

M.-S. Kim · D.-Y. Kwon

Korea Food Research Institute, Kyungki-do 463-746,

Republic of Korea

\section{S.-W. Chae · H.-J. Chae $(\bowtie)$}

Institute of Cardiovascular Research, School of Medicine,

Chonbuk National University, Jeonju, Chonbuk,

Republic of Korea

e-mail: hjchae@chonbuk.ac.kr
Keywords Apoptosis - Boswellia serrata - ER stress . Human cervical carcinoma

\section{Introduction}

The successful eradication of cancer cells through apoptosis-programmed cell death is the ultimate aim of non-surgical treatments. Essentially, all cytotoxic drugs currently in clinical use induce the apoptosis of malignant cells when they do work. Microtubule binding drugs, DNA-damaging agents, nucleosides and other types of medicine including herbal medicines are important weapons in the treatment of cancer. Traditional herbal medications have been re-evaluated by clinicians on account of their fewer side effects and suitability for long-term use, compared with chemically synthesized medicines.

The gum resin of Boswellia serrata (BS), a type of deciduous tree grown in the drier parts of China, Korea and India, has been used in traditional medicine to treat inflammatory and arthritic diseases [1,2]. Besides the antiinflammatory effects, several studies on tumor cells have suggested that Boswellic acids, a component of BS, have anticancer effects [3, 4].

Cervical carcinoma is one of the most common cancers in females. It has been demonstrated that human cervical carcinoma cells appear to retain their functional apoptotic machinery because they respond to a wide spectrum of stimuli by undergoing apoptotic death [5, 6]. In this study, the apoptotic effect of BS was examined in human cervical carcinoma cells, HeLa cells. The signal transduction pathway underlying BS-induced apoptosis was investigated. 


\section{Materials and methods}

\section{Materials}

D-MEM, FBS, and tissue culture reagents were obtained from Life Technologies. The anti-GRP 78, CHOP and actin antibodies were supplied by Santacruz (Santa Cruz, Calif., USA). All other chemicals were purchased from Sigma. All reagents were at least of analytical grade.

\section{Preparation of BS extracts}

Hot water-extracted BS was prepared and concentrated to $1 \mathrm{~g}$ of medicine per $\mathrm{ml}$ of distilled water. After dissolution and mixing in $\mathrm{PBS}$ at $37^{\circ} \mathrm{C}$ for $30 \mathrm{~min}$, the concentration was adjusted to $100 \mathrm{mg} / \mathrm{ml}$. This solution was then centrifuged $(1200 \mathrm{~g}, 30 \mathrm{~min})$ to remove any insoluble ingredients. The supernatant was sequentially passed through $0.45 \mu \mathrm{m}$ filters for sterilization. The extracts were used in all experiments.

\section{Cell culture}

The clonal human cervical carcinoma HeLa cells were obtained from ATCC. The cells were maintained in D-MEM supplemented with $10 \%$ FBS, penicillin G (100 U/ml), and streptomycin $(100 \mu \mathrm{g} / \mathrm{ml})$ in a humidified incubator.

\section{Measurement of calpain activity}

The calpain activity was measured in the cytosolic fraction using a calpain assay kit purchased from Calbiochem (San Diego, Calif., USA). The assay is based on the fluorometric detection of the cleavage of the calpain substrate, SucLeu-Tyr-7-amino-4-methylcoumarin (Suc-Leu-Tyr-AMC, $50 \mu \mathrm{M})$. The reaction buffer $(145 \mathrm{mM} \mathrm{NaCl}, 100 \mathrm{mM}$ Tris$\mathrm{HCl}, \mathrm{pH} 7.3$ ) and substrate were then added to all samples. The reaction was carried out in a 96 -well plate that was protected from light and incubated for $1 \mathrm{~h}$ at $37^{\circ} \mathrm{C}$ with constant shaking. The samples were read in a Gemini fluorescence microplate reader (Molecular Devices) using $360 \mathrm{~nm}$ excitation and $430 \mathrm{~nm}$ emission filters. All measurements were performed in triplicate, and repeated with heart extracts in two independent experiments.

Western blot analysis

Western blot analysis was performed as described previously [7]. Briefly, whole-cell lysates were generated using a buffer consisting of $1 \%$ Nonidet P-40, $50 \mathrm{mM}$ HEPES (pH 7.5), $100 \mathrm{mM} \mathrm{NaCl}, 2 \mathrm{mM}$ EDTA, $1 \mathrm{mM}$ pyrophosphate, $10 \mathrm{mM}$ sodium orthovanadate, $1 \mathrm{mM}$ phenylmethylsulfonyl fluoride and $100 \mathrm{mM}$ sodium fluoride. Equal amounts of the lysates were subjected to sodium dodecyl sulfate-10\% polyacrylamide gel electrophoresis and transferred to Immobilon-P membranes (Millipore) in a transfer buffer [25 mM Tris, $192 \mathrm{mM}$ glycine, 20\% (vol/vol) methanol]. The membranes were first rinsed in Tris-buffered saline (TBS: $10 \mathrm{mM}$ Tris [pH 7.4], $150 \mathrm{mM} \mathrm{NaCl}$ ) and then blocked overnight at room temperature in TBS-5\% bovine serum albumin (BSA). Various antibodies including the anti-Bax antibody were each used at a dilution of 1:1,000 in TBS-5\% BSA. The antibody-antigen complexes were detected using horseradish peroxidase-conjugated protein A or horseradish peroxidaseconjugated goat anti-rabbit immunoglobulin G (Bio-Rad) and a chemiluminescent substrate development kit (Kirkegaard and Perry Laboratories). An equal loading was determined by the presence of $\beta$-actin.

Statistical analysis

The data was analyzed by one-way analyses of variance using Microcal Origin software. The differences between the treated samples were analyzed using the individual contrast when the factor consisted of more than two levels. $P$ values $<0.05$ were considered significant.

\section{Results and discussion}

Bosellia serrata extract induces apoptosis in Hela human cervical carcinoma cells

The anti-cancer effect of Bosellia serrata has been studied [3, 4, 8]. Therefore, the HeLa human cervical carcinoma cells were treated with the water extracts of BS. The BS extracts induced apoptosis in a dose-dependent manner, particularly at concentrations ranging from 0.5 to $2 \mathrm{mg} / \mathrm{ml}$. Hoechst-staining showed a significant increase in the number of apoptotic cells in the BS-treated cells. The number of Annexin V and Propidium iodide-positively stained cells was also higher in the BS-treated cervical carcinoma cells. This shows that the water extract of BS induces cell death in HeLa cervical carcinoma cells (Fig. 1).

Bosellia serrata extract enhances the expression of the ER stress marker proteins in HeLa human cervical carcinoma cells

There are two-apoptosis mechanisms, the intrinsic and extrinsic pathways in the cell death field [9]. Recently, 

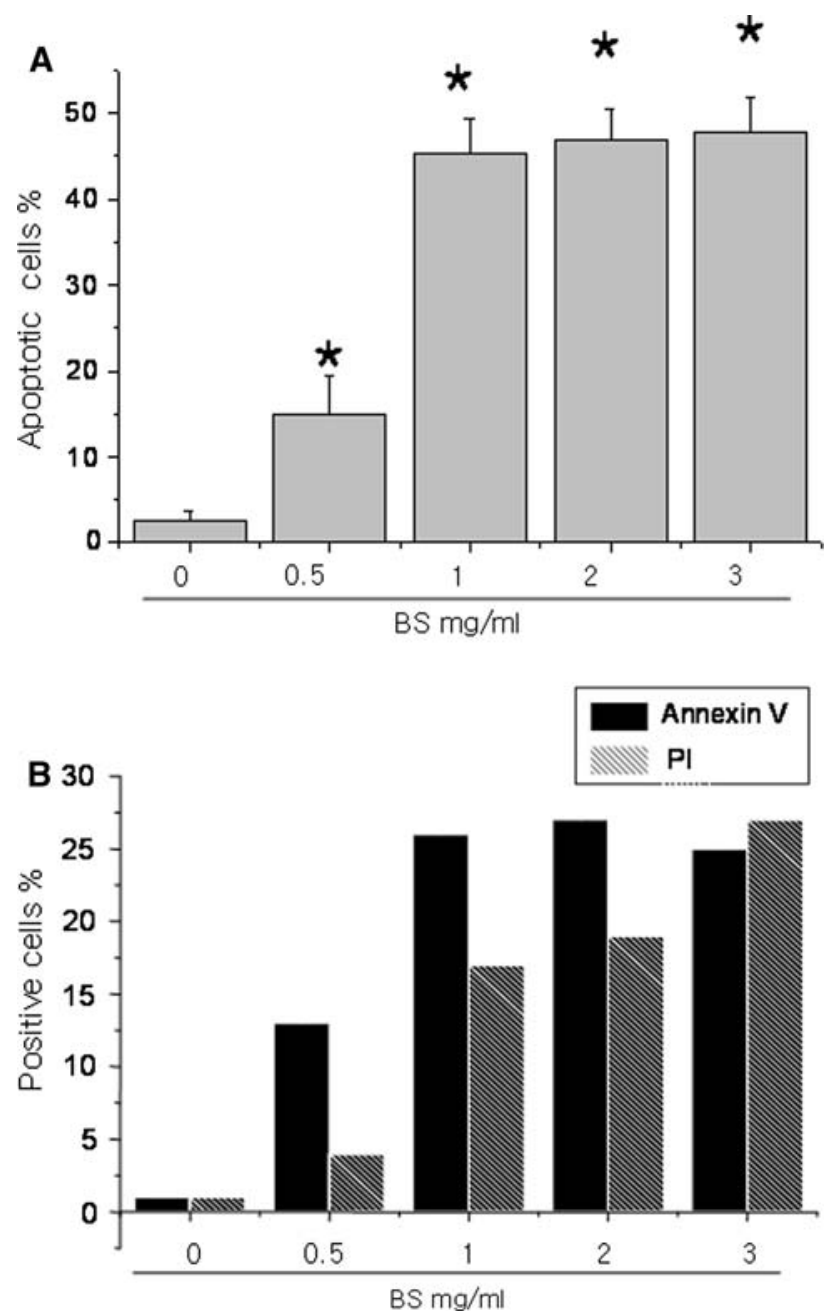

Fig. 1 Bosellia serrata induces apoptosis in HeLa human cervical carcinoma cells. HeLa cells were treated with the indicated doses of BS and incubated for $48 \mathrm{~h}$. The cells were stained with $10 \mu \mathrm{M}$ Hoechst dye and the apoptotic cells were measured (a). In parallel, the cells were stained with PI and AnnexinV and the positive stained cells were counted using FACS (b). Asterisks are significantly different from the control $(P>0.05)$

another pathway, an ER stress-associated mechanism, was reported [10]. On the other hand, therapeutic approaches using the apoptosis concept, such as anti cancer therapy, were performed, and another apoptosis mechanism was recently suggested to both explain the apoptosis itself and develop an anti-cancer therapy. The BS extract can be a candidate in the field of anti-cancer therapy. Therefore, this study examined the ER stress proteins in this system. GRP78 and CHOP are well known apoptosis-associated proteins. Figure $2 \mathrm{a}$ shows that GRP78 and CHOP were strongly expressed in the BS-treated cells in a time dependent manner. An apoptosis-triggering dose, 0.5, 1 and $2 \mathrm{mg} / \mathrm{ml}$ of BS triggered the expression of the two ER stress proteins (Fig. 2b).

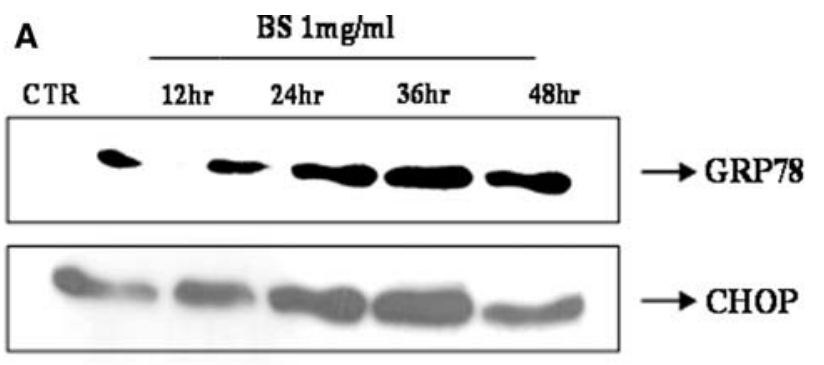

B $\quad$ BS (mg/ml)

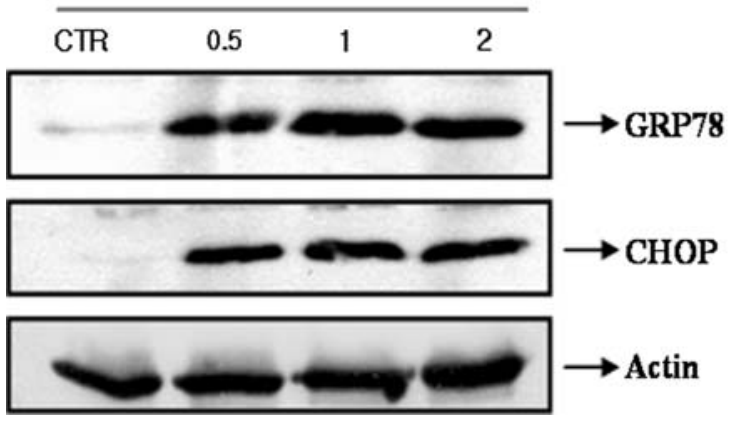

Fig. 2 Bosellia serrata increases the level of GRP78 and CHOP expression in HeLa human cervical carcinoma cells. a HeLa cells were treated with $1 \mathrm{mg} / \mathrm{ml}$ BS for $0,12,24,36$ and $48 \mathrm{~h}$. The cell lysates were analyzed in a SDS-PAGE. b HeLa cells were treated with the indicated doses of BS for $24 \mathrm{~h}$ and the cell lysates were analyzed as described in Materials and methods

Although there is some controversy regarding the cell physiological association between the expression of the ER stress protein and apoptosis, prolonged ER stress was found to increase apoptosis with no adaptation. Considering that the expression of the ER stress proteins was consistently higher in the BS-treated cells, the expression may be directly related to the BS-induced apoptosis in human cervical carcinoma cells.

Bosellia serrata extract induces the activation of calpain in HeLa human cervical carcinoma cells

Calcium is considered one of the second messengers strongly involved in ER stress signaling [11, 12]. Furthermore, calcium-binding protein-calpain is believed to be involved in the mechanisms associated with ER stress [13]. Therefore, the calpain activity was measured in the BS treated cells. BS extract stimulated the activity of calpain in a time and dose-dependent manner (Fig. 3a, b). It was difficult to measure the calcium level in the BS-treated cells because the BS has an endogenous color. However, calcium might be an important messenger in BS-induced apoptosis of HeLa human cervical carcinoma cells considering the expression of the ER stress proteins and calpain activity. 
Fig. 3 Bosellia serrata increases the activity of calpain in HeLa human cervical carcinoma cells. a HeLa cells were treated with $1 \mathrm{mg} / \mathrm{ml} \mathrm{BS}$ for $0,12,24,36$ and $48 \mathrm{~h}$. b HeLa cells were treated with the indicated doses of BS for 24 h. a, b The calpain activity was measured as described in Materials and methods. Asterisks are significantly different from the control $(P>0.05)$
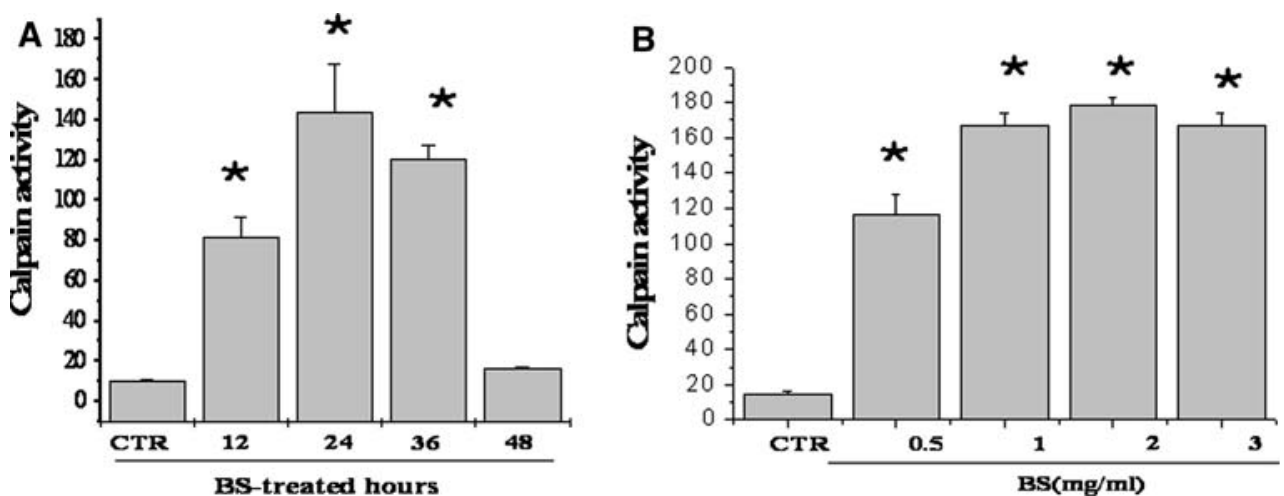

Acknowledgments The study is supported by the Korean Research Foundation Grant funded by the Korean Government (KRF-2005E00021) and by KOSEF for Biofood Research Program, Ministry of Science and Technology.

\section{References}

1. Kamath YJ, Asad M (2006) Effect of hexane extract of Bosellia serrata oleo-gum resin on chemically induced liver damage. Pak J Pharm Sci 19(2):129-133

2. Chevrier MR, Ryan AE, Lee DY, Zhongze M, Wu-Yan Z, Via CS (2005) Bosellia serrata extract inhibits TH1 cytokines and promotes $\mathrm{TH} 2$ cytokines in vitro. Clin Diagn Lab Immunol 12(5):575-580

3. Liu JJ, Nilsson A, Oredsson S, Badmaev V, Zhao WZ, Duan RD (2002a) Boswellic acids trigger apoptosis via a pathway dependent on caspase- 8 activation but independent on Fas/Fas ligand interaction in colon cancer HT-29 cells. Carcinogenesis 23(12):2087-2093

4. Liu JJ, Nilsson A, Oredsson S, Badmaev V, Duan RD (2002b) Keto- and acetyl-keto-Boswellic acids inhibit proliferation and induce apoptosis in Hep G2 cells via a caspase-8 dependent pathway. Int J Mol Med 10(4):501-505

5. Gruber BM, Anuszewska EL, Bubko I, Gozdzik A, Priebe W, Fokt I (2005) Relationship between topoisomerase II-DNA cleavable complexes, apoptosis and cytotoxic activity of anthracyclines in human cervix carcinoma cells. Anticancer Res 25(3B):2193-2198

6. Abraham R, Schafer J, Rothe M, Bange J, Knyazev P, Ullrich A (2005) Identification of MMP-15 as an anti-apoptotic factor in cancer cells. J Biol Chem 280(40):34123-34132

7. Chae HJ, Chae SW, Kang JS, Bang BG, Cho SB, Park RK, So HS, Kim YK, Kim HM, Kim HR (2000) Dexamethasone suppresses tumor necrosis factor-alpha-induced apoptosis in osteoblasts: possible role for ceramide. Endocrinology 141(8): 2904-2913

8. Flavin DF (2007) A lipoxygenase inhibitor in breast cancer brain metastases. J Neurooncol 82(1):91-93

9. Reed JC (2006) Drug insight: cancer therapy strategies based on restoration of endogenous cell death mechanisms. Nat Clin Pract Oncol 3(7):388-398

10. Xu C, Bailly-Maitre B, Reed JC (2005) Endoplasmic reticulum stress: cell life and death decisions. J Clin Invest 15(10):26562664

11. Nakano T, Watanabe H, Ozeki M, Asai M, Katoh H, Satoh H, Hayashi H (2006) Endoplasmic reticulum $\mathrm{Ca}^{2+}$ depletion induces endothelial cell apoptosis independently of caspase-12. Cardiovasc Res 69(4):908-915

12. Sanges D, Marigo V (2006) Cross-talk between two apoptotic pathways activated by endoplasmic reticulum stress: differential contribution of caspase-12 and AIF. Apoptosis 11(9):1629-1641

13. Nakagawa T, Yuan J (2006) Cross-talk between two cysteine protease families. Activation of caspase-12 by calpain in apopotosis. J Cell Biol 150(4):887-894 